\title{
A PHILOSOPHER's STONE: IRON INTO GOLD?
}

\author{
By Charles B. Miller
}

$\mathrm{O}$ N MAY 20, 1990, an article titled "Iron dumped in ocean may fight global warming" by William Booth of The Washington Post appeared in Sunday papers around the United States. A notion quietly talked about for several years in oceanographic circles was suddenly news. Those quiet oceanographers started yelling at each other and at newspaper editors. Some said alleviating iron-limitation of phytoplankton growth might sink gigatons of carbon from the atmosphere into the deep sea; nonsense, said others. Given the speed at which news appears and again vanishes in the electronic age, the public flap is long over. However, the underlying scientific issues remain important and interesting. Therefore, we have assembled a set of four papers covering the background for the notion that iron availability may set the limit on phytoplankton stocks and growth rates in large regions of the world oceans.

The notion that iron might be a key limiting plant nutrient in the sea goes back to the work of T. J. Hart and others in the Discovery Expeditions to the southern ocean during the $1920 \mathrm{~s}$ and 1930s. Later, iron was mentioned by H. H. Gran, Trigve Braarud, H. W. Harvey, and others as a possible limiting factor, along with comments on the difficulty of studying its role because of recurring contamination. Iron was again advanced in the early 1960s by David Menzel and John Ryther as an explanation for productivity observations in the Sargasso Sea, and substantial research on iron nutrition of phytoplankton has been done from the 1960 s to the present by Joyce Lewin, Robert Guillard, Francois Morel, William Sunda, and others. However, John Martin opened the current chapter of the iron-limitation story by studies in the subarctic and equatorial Pacific and in the southern ocean. His contribution is based

Charles B. Miller, College of Oceanography, Oregon State University, Corvallis, OR, 97331. USA. on clean techniques for water collection, making possible uncontaminated iron profiles and ironaddition experiments. He tells the story himself here in the first article of our series.

Iron limitation, if it is a recurring key phenomenon in oceanic ecology, needs to be understood in the contexts of the physiology of iron utilization and of supply and removal processes. Francois Morel, Neil Price, and John Rueter have all been working on the physiology, using sophisticated tools of modern aquatic chemistry. They review their work in the second paper of our series. Supply of iron to the ocean far from land appears to be principally aeolian, i.e., carried on the wind. This conclusion comes largely from the work of Robert Duce and his colleagues, a group of whom have collaborated on our third article.

No single limiting factor can be all that makes any oceanic ecosystem what it is. The iron-limitation hypothesis has the feel of "philosopher's stone," the objective of alchemy. A few scrapings from this ardently sought stuff would cure disease or turn molten iron into gold. We often seek such a single essence in our oceanographic problems much as alchemists sought the pure spirit of substance. But in ecology we sooner or later are confronted with other complexities. One possibly iron-limited ecosystem is the subarctic sector of the Pacific. This region has been the subject of long study by the Subarctic Pacific Ecosystem Research (SUPER) Group. The fourth paper is a review by SUPER of how iron limitation might fit into a comprehensive understanding of high-seas ecology.

We hope that this suite of papers will give readers the basic background of the current debate about iron limitation of phytoplankton production. More extensive information will be published soon by the American Society for Limnology and Oceanography in a symposium volume being edited by Sallie Chisholm and Francois Morel. $\square$
... iron availability may

set the limit on

phytoplankton stocks

and growth rates in

large regions of the

world oceans. 